\title{
Research on Domestic Bank Customer Satisfaction Based on Logistic Regression Analysis
}

\author{
Chengming Chang \\ Department of Information Management \\ Hwa Hsia University of Technology \\ Taipei, Taiwan R.O.C
}

\begin{abstract}
As modern people have higher expectations for banking services and hope to get perfect services, the banking service satisfaction is more and more important, and competition among banks grows with each passing day. Therefore, I studied service satisfaction rating among banks so as to improve the relationship between businesses and customers in the future. The results of this analysis may provide references for banks to make decisions and to provide diversified services to further meet customer needs. In this study, we carries out an investigation about service satisfaction of 35 banks in Taiwan, and analyzes banking satisfaction performance using principal component regression, decision tree and logistic regression.
\end{abstract}

Keywords-satisfaction; quality of service; decision trees; logistic regression

\section{INTRODUCTION}

In recent years, due to the opening of financial markets, the business pattern of financial institutions has gradually moved towards liberalization and become highly competitive. After the financial liberalization, the competition among banks shifted from price to non-price competition. Banks used media advertisement to enhance their professional and quality services in the heart of customers, and positively changed the negative attitudes to positive images. Hence, banks must improve quality of service to achieve customers' satisfaction to stay competitive. Therefore, the purpose of this study is to investigate the impact of banking on quality of service and customer satisfaction. Enhancing quality of service and consumer's willingness of consumption and creating better and more favorable competitive trends have become important goas of banks in their future operations.

This study focuses on consumer satisfaction surveys for all banks. The booming development of the financial industry has led to the fierce competition among banks. Only thinking like a customer will make the customer satisfied, if the quality of service of a bank is not good, it is likely to cause the loss of customers, and the bank will finally be merged or eliminated. As the banking industry is a highly competitive service industry, meeting customer needs is very important. This study will explore how to enhance customer satisfaction to give references for Taiwan banks.

\section{REVIEW}

Correlative papers about customer satisfaction include:
Cardozo (1965) believes that customer satisfaction will increase customers' repurchase behaviors of and their willingness of buying other products.

(Dauw-Song Zhu et al, 2007) believe that customers contact frequently with bank clerks, and the service value accepted by customers is delivered by clerks, therefore, the service value is greatly associated with bank staff's expertise and communication skills.

Zeithaml and Bitner (1996) argue that customer satisfaction is an integrative assessment of tangible and intangible products, including service value, product quality, price factor, situational factor and personal factors, etc.

Ming Chang Lee (1995) finds out service quality has a significant impact on the profitability; Su Min (1998) takes domestic aviation services for empirical research object, studies on the interactive relationship among employees, customer satisfaction and business performance of companies.

Huang Wenyu (2000) discusses on corporate banking finance, and it is found that quality of service delivered to customers is positively correlated with bank performance.

Stafford (1994) explores service quality dimensions which are valued by customers. The survey found that the interaction between staff and customers is the most important service quality dimension considered by customers; customers not only hope that bank employees are polite, but also expect that they are kind and professional.

Wang Naijun (2006) uses correlation analysis to analyze the relationship between quality of service and overall customer satisfaction. The result indicates that: different groups' thought on service quality dimensions have significant differences.

Ching-Wei Huang (2003) conducted a questionnaire survey taking domestic customers of Bank of Communications for the example, and used regression analysis to verify the impact of service quality on customer satisfaction. The results found that: customers' awareness of service quality in respect of efficiency and security, equipment and correctness has significant differences.

\section{RESEARCH METHODS}

This study analyzes survey data of quality of service in Taiwan banks, separately studying on service satisfaction of customers for 35 state-owned and private banks, and getting performance value by grey prediction. It also builds 
performance detection model using three kinds of data mining technology including primary component regression, decision trees and logistic regression.

\section{A. Grey Relational Analysis}

Grey theory was proposed by Professor Deng Julong (Deng, 1982) from Huazhong University of Science and Technology, and it was used in predictive analysis, which can fully analyze limited data messages and achieve the expected future value. The theory mainly analyzes the system and understands the state of the system by forecasting method and decision-making method under the premise of uncertainty of the system model and incomplete information.

\section{B. Logistic Regression}

Logistic regression, also called a logit model, is used to model dichotomous outcome variables, such as "success" or "failure." Logistic regression and traditional regression are similar in nature, but it is used to deal with the problems with category information. As the category information belongs to the category of discrete information, so we have to turn this discrete data into continuous data between 0 and 1 , and perform a regression analysis for the continuous data after conversion.

The main purpose of logistic regression is to determine the relationship between categorical response variables and a series of explanatory variables, therefore, the biggest difference from regression analysis is the different reaction patterns of variables, so the logistic regression also need to accord with general assumptions of the traditional regression analysis, which is to avoid collinearity problems among the explanatory variables, and in line with normal distribution and avoid auto correlated residual and other statistical basic assumptions. When response variables are discrete type, and there are only two or a few categories, the logistic regression becomes one of the most standard methods of analysis.

\section{Decision Trees}

Decision trees usually work top-down. Every decision or event could lead to two or more events and lead to different results. These decision branches look like branches of a tree, thus it is called a decision tree, and each segment or branch is called a node. A record enters a decision tree from the root, and will enter a leaf node by using different test algorithms, and the process will be repeated until the data reaches the leaf node.

From the root to each leaf, it has a unique path, and the path is used as an expression of data classification rules. There are several ways of classification, but the purpose is the same, that is to make the best classification for the target. A decision tree can be binary or hierarchical. There are three criteria measuring each node, that is, number of data passing through the node; and if it is a leaf node, then it includes path classification and correct proportion of leaf nodes.

\section{Principal Component Regression (PCA)}

Principal Components Analysis (PCA) is an exploratory multivariate statistical technique for simplifying complex data sets. PCA is often used to reduce the dimensionality of the data set, while maintaining the feature of data concentration. This is to transform a high-dimensional dataset into a smaller- dimensional subspace. Such low-dimensional components are often able to keep the most important aspects of data. However, this is not certain, depending on the specific application. Because the principal component analysis is dependent on the data provided, the accuracy of the data has a great influence on the analysis result. The principal component regression is to reduce the variation of data sets and to reduce the complexity of the general multiple regression, and thus maintain the accuracy of prediction.

\section{EMPIRICAL STUDY}

\section{A. Sample Data}

Based on survey report of service quality of banks in Taiwan conducted by Louis Harris Internation Taiwan in 1995 and several new banks' information, the study analyzes test data, which includes 11 state-owned banks and 24 private banks. Banking service satisfaction factors include service attitude (X1), empathy to customers (X2), service efficiency (X3) professional or not (X4), the bank's cleanness of environment (X5), convenience of bank location (X6) convenience of peripheral services (X7), the overall environmental design (X8) and interior network accessibility (X9). The descriptive statistics values of satisfaction factor are shown in Table 1. This paper analyzes service satisfaction performance of 35 banks with survey data and main factors of satisfaction, and builds performance detection model for service satisfaction.

TABLE I. DESCRIPTIVE STATISTICS OF CORRELATION FACTOR

\begin{tabular}{rccccc|cccc} 
Factor & $\mathbf{X 1}$ & $\mathbf{X} 2$ & $\mathbf{X 3}$ & $\mathbf{X} 4$ & $\mathbf{X 5}$ & $\mathbf{X 6}$ & $\mathbf{X 7}$ & $\mathbf{X 8}$ & $\mathbf{X 9}$ \\
\hline \multirow{2}{*}{ Max } & 4.6 & 4.0 & 4.0 & 4.2 & 4.1 & 4.9 & 3.9 & 4.1 & 4.6 \\
& 5 & 2 & 6 & 9 & 2 & 2 & 8 & 4 & 3 \\
\multirow{2}{*}{ Min } & 3.1 & 2.6 & 2.9 & & 2.7 & 3.3 & 2.6 & 2.8 & 2.8 \\
& 5 & 5 & 3 & 2.5 & 2 & 8 & 7 & 7 & 2 \\
\multirow{2}{*}{ Avg } & 3.9 & 3.3 & 3.4 & 3.6 & 3.4 & 4.4 & 3.4 & 3.4 & 3.7 \\
& 2 & 4 & 4 & 1 & 0 & 7 & 6 & 2 & 6 \\
\hline \multirow{2}{*}{ Std } & 0.3 & 0.3 & 0.2 & 0.3 & 0.3 & 0.4 & 0.3 & 0.3 & 0.4 \\
& 5 & 2 & 6 & 9 & 1 & 2 & 3 & 0 & 1
\end{tabular}

Performance Analysis of Bank Satisfaction Using Grey Relational Analysis (GRA).

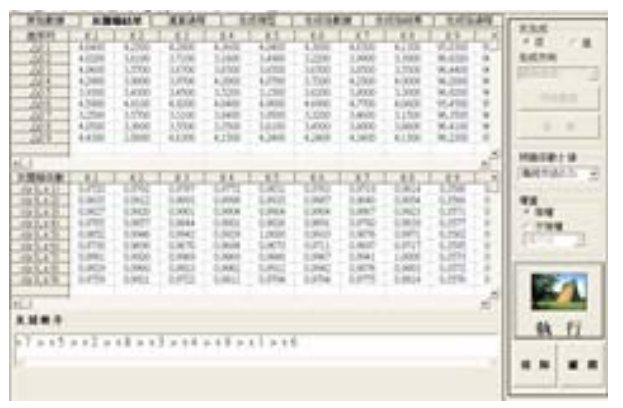

FIGURE I. DIAGRAM OF QUESTIONNAIRE RESULT OF 35 STATEOWNED BANKS USING GREY RELATIONAL ANALYSIS

Figure 1. Diagram of questionnaire result of 35 state-owned banks using grey relational analysis Figure 1 shows that the convenience of peripheral services (X7) is the best, which indicates that peripheral services are main advantages. In order to improve quality of service for customers, banks provide 
various peripheral services to make customers feel very convenient, such as ATM services, short message service, credit card application and foreign currency exchange services; the worst customer service is convenience of bank location (X6), which may be caused by inconvenient traffic due to remote locations or intensive distribution of offices. Therefore, banks should evenly distribute their office locations to increase convenience.

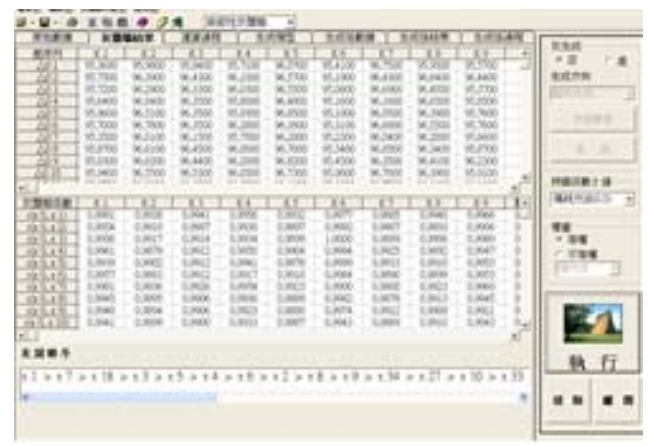

FIGURE II. DIAGRAM OF QUESTIONNAIRE RESULT OF 35 PRIVATE BANKS USING GREY RELATIONAL ANALYSIS

The result shows that E.SUN Bank has the best service attitude (X1). E.SUN Bank provides the best quality of services to customers. It surely has a full-fledged educational training system for employees, thus it performs best in consumer service.

\section{B. Construction and Cross-Validation of Three Models}

The principal component regression, decision trees and logistic regression are used for modeling. The variables include $\mathrm{x} 1$ - $\mathrm{x} 9$ as independent variable (X), and good performance (“0”) and poor performance (“ 1 ”) as a result of prioritized performance values of grey relational analysis as dependent variables (Y). We divide 35 sample banks into 7 groups and 5 records, and conduct a cross-validation of the accuracy on 6group models and 1 test model. The verification results are shown in Table 2.

TABLE II. PREDICTING OUTCOMES OF THREE MODELS

\begin{tabular}{|c|c|c|c|}
\hline Prediction Model & $\begin{array}{c}\text { Principal } \\
\text { Component }\end{array}$ & $\begin{array}{c}\text { Decision } \\
\text { trees }\end{array}$ & $\begin{array}{c}\text { Logistic } \\
\text { regression }\end{array}$ \\
\hline Misclassification error & $3 / 10$ & $2 / 10$ & $1 / 10$ \\
\hline Average error & 0.193822 & 0.140162 & 0.139213 \\
\hline
\end{tabular}

We can see from Table 2 that whether it is the analysis result of misclassification error or average error, the logistic regression gets the most accurate result. In the process of model building, principal component is relatively complicated, and such feature might provide reference for relevant researchers

\section{CONCLUSION AND SUGGESTION}

The main contribution of this study is to study on the customer satisfaction of banks. After grey relational analysis, we find out that E.SUN Bank has the highest customer satisfaction rate. We use three kinds of data mining technology, namely, principal component regression, decision trees, and logistic regression, to predict. If a new bank enters the Taiwan market in the future, we just need to bring nine variables. Based on the analysis by the misclassification rate and the average error, logistic regression has the most accurate result, followed by decision trees. However, both methods have their own characteristics; the researchers may decide in which way should be modeled according to their needs.

\section{REFERENCES}

[1] Dauw-Song Zhu, Chen-huan Hong, Yi-An Chen (2007), “Applying Service Profit Chain to Build Customer Loyalty-An Empirical Study in Banking Industry”, Journal of Customer Satisfaction, Vol. 3, No. 2, pp. 95-120.

[2] Ming Chang Lee (1995), The Causal Relationship Between Service Quality, Customer Satisfaction and Profitablity in Taiwan Banking Industry, unpublished master's thesis of National Yunli University of Science and Technology Institute of Business Administration

[3] Huang Wenyu (2000), Study on Service Quality of Bank Industry and Business Performance, unpublished master's thesis of National Chung Cheng University Accounting Office.

[4] Wang Naijun (2006), A Study of Service Quality and Customer Satisfaction and Customer Loyalty: A Case Study of the King's Town Bank in Chiayi City, National Chiayi University, Department of Management, master's thesis.

[5] Ching-Wei Huang (2003), Study on the Impact of Service Quality and Customers Satisfaction for the Privatization of State-Owned Business

[6] Chiao Tung Bank as an Example, Department of Business Administration Chaoyang University of Technology, thesis for the degree of master.

[7] Weng Chongxiong (1993), Study on the Service Quality and Service Value---Take Banking Sector as an empirical object, National Taiwan University, Business School, doctoral thesis

[8] Cardozo, R. N. (1965), “An Experimental Study of Customer Effort, Expectation and Satisfaction,” Journal of Marketing Research, Vol. 2, No. 3, pp. 244-249.

[9] Zeithaml, V. A. and M. J. Bitner (1996), Services Marketing, pp. 30-51

[10] Stafford, M.r.Demographic (1996) discriminators of service quality in the banking industry, Journal of Service Marketing 10(4):6-22.

[11] Deng, J. (1982), The control problems of grey system, System \& Control Letters, No.5, pp. 288-294. 